\title{
What the Next Bioethics law says about us
}

\author{
Jean Philippe Pierron* \\ Faculty of Philosophy, University Jean Moulin Lyon, France
}

*Corresponding author: Jean Philippe Pierron, Faculty of Philosophy, University Jean Moulin Lyon, Les Belles Lettres, France.

To Cite This Article: Jean Philippe Pierron. What the Next Bioethics law says about us. Am J Biomed Sci \& Res. 2019 - 6(1). AJBSR.MS.ID.000988. DOI: 10.34297/AJBSR.2019.06.000988.

Received: 戝 September 19, 2019; Published: 眥 October 31, 2019

\section{Opinion}

What does the next bioethics law say about us? The preparation of the so-called "bioethics" law offers the opportunity to focus on how our society responds to the question of what it is for a human desiring and suffering. It follows what our socio-political practices place under the revolutionary figure of "states-general" of bioethics. It comes to conclude, provisionally since these laws are "revisable", a rare citizen moment when one thinks about it. The one where everyone, if he wanted to - the hundreds of organized debates did not mobilize millions of people - could come to find information and debate in a democratic framework, aware of the ethical pluralism of conflicting traditions. But also, able to argue, to agree on disagreements.

There is something rejoicing that a human community is taking up extremely intimate and incomparable questions. Indeed, the four components of the future law concerning medical assistance to procreation, transplants, genetics and research mark the territories of a humanity that works to understand the enigma of the body desiring, procreative, suffering and dying. This applies to sex and the desire of a child in the opening of the medical assistance to the procreation to the couples of women or the freezing of oocytes for the women of more than 32 years; meditation on our "Umbilical Consciousness" and the origin by the birth registration under AMP on the integral birth certificate to prevent new family secrets related to these techniques; the definition of the disease with genomic medicine, death and the status of donation with the opening to new transplants.

That our society, by the law, this work of self-narrative shows that it gradually becomes aware, as and when revisions, that it delegates much to "the" medicine. It thus measures the importance of its regulation and its citizen watch since "medicine" intervenes in an ethical, legal and symbolic framework that it defines for itself. Thus, the telemedicine which discusses the territorial justice, the medical assistance to the procreation which supports the desire of child without confounding it with a right to the child, the gift and not the commercial exchange within the framework of the grafts etc. mobilize ethical guidelines. But they also call for political positions on the idea that our society has of what is a truly human life deployed within the limits that corporeality, disease and suffering assign to it. Thus, the laws of bioethics as their name indicates are not the expression of an oxymoron opposing ethics to law. They invest the point of tension between the most intimate desire to be that the ethics and the most public that accompanies the law and the law accompanies in the dimension of juridicization - and not only of judiciarization - which characterizes the right of the health. These questions as painful as delicate as the desire of a child confronted with the implacable biological clock in the case of egg freezing, the right access to health despite the scarcity of resources, the impact of data processing massive data on the nature of medical interpretation are discussed. The most spectacular could be said in shameless words with regard to the lives they designate - access to origins, the MPA for same-sex couples - are in the spotlight. This because they engage our condition to be desiring and suffering more obviously than in more technical but not less important issues (genomic medicine, big data) where this same condition is nevertheless questioned. Which forbids to say, too hastily, that this law would devote a transhumanist impulse!

In future debates that are sure to be born, and fortunately, several points of attention deserve to be highlighted.

The first is not to confuse innovation which is a fact linked to the developments of new medical techniques and progress which is a value judgment focused on this fact. The third revision of the law since 1994 must question us: does the law only follow an innovation or is it regulating it because of new possibilities or a modification of societal expectations?

Then, how in the discussion to come to the point of view of the other without going into the easy opposition, - because who can claim in these matters to be in "the sense of history" - between conservatives and progressive? 
In addition, at the time of the ecological transition, will we be able to make progress by learning to think together, within the same eco-social-responsible paradigm, the issues of medical bioethics with those related to the issues involved? to non-humans and more broadly to nature?
Finally, will we avoid in the discussion the teleological temptation of a legal comparatism between the legislations of the different countries, leading one to believe that to legislate or not to legislate in these matters would be in advance or behind the others? 